Published online 05 24, 2021

ISSN 2763-5392

\title{
The importance of Guidance and Mobility (GM) for the teacher of Specialized Educational Care (SEC)
}

\author{
Natali Maria Andrade da Silva ${ }^{*}$; Nadja Maria Barbosa ${ }^{2}$; Artur José Braga de Mendonça ${ }^{3}$ \\ 1 Postgraduate students in the Guidance and Mobility Program of the Alpha Faculty - Pernambuco - Brazil. \\ 2 Postgraduate students in the Guidance and Mobility Program of the Alpha Faculty - Pernambuco - Brazil \\ 3 Advisor in the Guidance and Mobility Program of the Alpha Faculty - Pernambuco - Brazil.
}

E-mail adresses: natalijesussempre@hotmail.com (Natali Maria Andrade da Silva), nadjablemos@gmail.com (Nadja Maria Barbosa), ajbmendonca@gmail.com (Artur José Braga de Mendonça)

${ }^{*}$ Corresponding author

\section{To cite this article:}

Silva, N. M. A.; Barbosa, N.M.; Mendonça, A.J.B. The importance of Guidance and Mobility (GM) for the teacher of Specialized Educational Care (SEC). International Journal of Sciences. Vol. 1, No. 3, 2021, pp. 65-70. ISSN 2763-5392

Received: 05 10, 2021; Accepted: 05 13, 2021; Published: 05 24, 2021

\begin{abstract}
The general objective of the article will be to present the Guidance and Mobility (GM) as necessary for the training of the specialized educational care professional (SEC). This objective will be achieved through the specific objectives, which will be: to study the performance of the ESA teacher and the little training of this professional in the area of visual impairment; to highlight the importance of training the teacher of the ESA classroom, in orientation and mobility, to facilitate accessibility in the face of some attentional barriers encountered by the visually impaired; to show the positive points of the ESA teacher having knowledge about GM. The problem will be the ignorance of the area of Guidance and Mobility. The method adopted is a qualitative methodological research, where an analysis and description will be made on the theme addressed, with the purpose of discussing and affirming the need of the ESA teacher to have in his basic education the knowledge about Guidance and Mobility, so that, within his/her performance, he/she has the capacity to develop the autonomy of his student, besides stimulating the learning of the same. Based on bibliographic research in articles, books and sites focused on this theme, the work will be addressed. Thus, it is expected, as a main result, that the professionals of the ESA understand the importance of training in GM, so that it is properly qualified to meet its student with visual impairment.
\end{abstract}

Keywords: Guidance and Mobility; Visual impairment; Teacher training.

\section{Introduction}

Guidance is the process of using the remaining senses to establish one's own position and relationship with other significant objects in the environment. Mobility is the ability to move safely, efficiently and comfortably in the environment, through the use of the remaining senses (WEISHALN, 1990). In this perspective, "Orientation and Mobility" (GM) comprises a set of techniques aimed at people with visual impairment, whose objective is to promote the acquisition of autonomous and independent movements, in addition to the mastery of the body, the discovery of space and the sense of spatial orientation. The mastery of these techniques encourages people with visual impairments to become independent in the personal, social, school and professional spheres (MENDONÇA E MATOS, 2019). Such concepts are necessary for the visually impaired person to move safely and efficiently, as well as for the understanding of the teacher responsible for that person about their role and how to play it in a positive and effective way.

Therefore, it is valid to talk about specialized educational care (ESA), being a special education service that identifies, elaborates, and organizes pedagogical and accessibility resources, which eliminate barriers to full participation of students, considering their specific needs (SEESP/MEC, 2008). In specialized educational care, the teacher should, together with the student, identify what he faces as a difficulty in the educational context, in order to understand what limits his learning and participation. Thus, the teacher should look for methods and strategies that will assist the student, promoting or expanding their possibilities of participation and performance in the activities of the school environment. identification of the barriers it faces in the common educational context and that prevent or limit it from participating in learning challenges at school.

It is known that the visually impaired person must be 
assisted by the SEC teacher, if he or she should have the ability and competence to create, discover and reinvent pedagogical strategies and activities consistent with the general and specific needs of his student. Therefore, it is understood that it is necessary that the ESA teacher has professional training focused on GM, so that he knows learning strategies, procedures, means of access to knowledge and information, as well as assessment instruments, appropriate to the visual conditions of the students, and promote effective assistance.

The present study arose from the need that we identified in training the professional in the ESA room in the qualification of orientation and mobility, we saw that he did not have the knowledge of these practices to guide the visually impaired person, so that he/she perceives the environment that surrounds her, using the remaining meanings, in the environment in which he is inserted in the school.

Therefore, the present work awed from the desire to contribute to the teacher's training in the ESA room due to their lack and lack of knowledge in this area, and to provide him with guidelines for the development of skills in order to improve the professional's adequate procedures in relation to Guidance and Mobility, so that they have a better interaction with the visually impaired. Thus, contributing to the process of social inclusion.

Following this line, the general objective of the article will be to present the Guidance and Mobility (GM) as necessary for the training of the specialized educational care professional (SEC). This objective will be achieved through the specific objectives, which will be: to study the performance of the ESA teacher and the little training of this professional in the area of visual impairment; to highlight the importance of training the teacher of the ESA classroom, in orientation and mobility, to facilitate accessibility in the face of some attentional barriers encountered by the visually impaired; to show the positive points of the ESA teacher having knowledge about GM.

This study leads us to approaches on Orientation and Mobility, regarding its importance as a program for the development of knowledge for the achievement of autonomy, independence and the inclusion of the visually impaired in society. Then, the approach focuses on accessibility and its importance, because where it does not install, a situation of vulnerability is established for people with visual impairment, in various aspects of their daily lives. We also report to the training of the Teacher of the ESA (Specialized Educational Care), his attributions, competencies, legal aspects that underlie the ESA, and the articulation of the work of this professional.

Thus, it is expected that the present will contribute in order to awaken the need for the training of the ESA teacher focused on Guidance and Mobility, in order to qualify this professional to be able to assist people with visual impairment in the action of getting around with maximum security and independence, as well as encouraging autonomy to develop their daily activities, leading it to be increasingly inserted in schools, in the labor market, in society as a whole.

\section{Literature Review}

\section{Guidance and Mobility}

Orientation and mobility, when properly worked, are served as a set of lesson plan that will enable the acquisition of autonomous and independent movements, in addition to the body domain, the discovery of space and the sense of spatial orientation (BRASIL, 2003).

The development of guidance and mobility of visually impaired people occurs as any individual, from birth. What will characterize the difference is the need for blind children to be stimulated as soon as possible through the remaining senses and the natural manipulation that occurs in the moments of exchange, bathing, feeding and caring, and should therefore start in the mother's lap and in the cradle where she acquires rich opportunities to experience spaces and movements. Therefore, this moment can be considered as the beginning of the construction of its Orientation and Mobility. In early intervention programs, some procedures should already be included for visually impaired children aimed at guidance and independent mobility in the future. It is important to emphasize that in these first years of life, parents are the main mediators in this construction and should actively participate in this program. When the child begins to attend school, new techniques can be introduced gradually and incorporated by the child, starting to be part of their day-to-day life. In this phase, the most direct mediator is the specialized teacher, who in partnership with parents and teachers of common class will help the child to build the necessary bases for his independence, not only in Orientation and Mobility, but also in the activities of autonomous and social life (GARCIA, 2001).

For Zengo, Seabra Junior and Moreira (2014), the mastery of these techniques encourages people with visual impairment to become independent in the personal, social, professional and school spheres, but it should be in mind that the skills will develop in the time of each individual, regardless of age or whether visual impairment has been acquired or congenital (MENDONÇA, 2018). This training will serve as a basis for the professional of the ESA room, this guidance and mobility will serve for the planning of the classes. Carletto (2007) states that: One should take into account not only chronological age, but at what point of development is this particular student. Which of your previous experiences can you successfully develop? Acting in this way, there is no risk that the activity is not significant and does not reach the proposed objective (MENDONÇA; MATOS, 2019).

For Mendonça et al. (2008, p. 67), guidance and mobility, it aims to help the visually impaired "to build the cognitive map of the space that surrounds it and move in this space, using a set of appropriate and specific techniques". Hoffmann (1999) defines GM as a broad and flexible process, composed of a set of motor, cognitive, social and emotional skills and a group of specific techniques (seer guide, protection and cane), which enable the visually impaired to 
know, relate and move independently and auton-omously in the various structures, spaces and situations of the environment.

Thus, through the Orientation and Mobility program, the visually impaired person can acquire new skills so that he can move with autonomy, independence and especially safely. GM can provide this individual with the diversification and qualification of locomotor experiences and, consequently, the exercise of motor and cognitive skills. This attitude promotes self-knowledge and confrontation in the face of difficulties, enabling the increase of confidence and security in its potentiality, as well as the verification of limitations. Therefore, gradually, the acquisition or reconquest of the feeling of self-confidence may occur.

\section{Accessibility}

The Law number 10,098, DECEMBER 19, 2000 (BRAZIL, 2003) establishes general standards and basic criteria for the promotion of accessibility for people with disabilities or reduced mobility, and provides other measures by removing barriers and obstacles in public roads and spaces, in urban furniture, in the construction and renovation of buildings and in the means of transport and communication. It has as definition of accessibility: possibility and condition of scope for the use, with safety and autonomy, of spaces, furniture, urban equipment, buildings, transport, information and communication, including its systems and technologies, as well as other services and facilities open to the public, for public or private use of collective use, both in the urban and rural areas, by people with disabilities or with reduced mobility; of a disabled person: one who has a long-term impediment of a physical, mental, intellectual or sensory nature, which, in interaction with one or more barriers, can obstruct their full and effective participation in society on equal terms with other people; and of a person with reduced mobility: one who has, for any reason, difficulty in movement, permanent or temporary, generating effective reduction of mobility, flexibility, motor coordination or perception, including the elderly, pregnant, lactating, person with a child and obese; Wording given by Law No. 13,146, 2015) (Validity).

In common sense, accessibility seems to highlight the aspects related to the use of physical spaces. However, in a broader sense, accessibility is a condition of possibility for the transposition of barriers that represent the barriers to the effective participation of people in the various spheres of social life. Accessibility is, therefore, a fundamental and indispensable condition for any and all processes of social inclusion, and is presented in multiple dimensions, including those of an attitudinal nature, physical, technological, informational, communicational, linguistic and pedagogical, among others. Therefore, the promotion of accessibility requires the identification and elimination of the various types of barriers that prevent human beings from performing activities and performing functions in the society in which they live, in conditions similar to other individuals (Secretary of Accessibility UFC, 2010).
Accessibility allows people with disabilities or reduced mobility to make it possible to get around in some places such as: schools, commercial establishments and services, on how best to make their building accessible, democratizing information, we seek to collaborate so that teachers in the ESA room, have integration techniques and practices, since they allow students more varied spaces for all people , eliminating physical barriers.

The term accessibility refers to the inclusive practice of doing that can be used by all people, whether disabled or not. In this context, accessibility can be understood in a way that people with some type of disability have autonomy in the exercise of their daily activities, it is the ability of this person to have mobility by enjoying the space safely in the same way as other people (SOUZA, 2017).

It is necessary to implement the necessary adjustments and arrangements that allow these people access and coexistence in the common space, not segregated, since incluir the disabled person in the social environment goes beyond inserting it in the activities of daily life, but rather adapting the environment so that it makes possible the insertion of the same.

\section{Training of the teacher of specialized educational care (SEC)}

The ESA (Specialized Educational Care) aims to promote special education as a form of learning exercise that passes teaching in its stages and modalities, in order to provide the necessary services and resources guiding their use within the common classroom of regular education. With this, it has the function to identify, elaborate and organize pedagogical and accessibility resources that allow the full participation of students, considering their specific needs. This encourages the training of students with a view to autonomy and independence in school and beyond.

According to Rosângela Machado (Pedagogue specialized in Special Education, specialized educational care-SEC stems from a new conception of special education, supported by decrees and resolutions. It is centered on the dimension of accessibility that ensures participation, activity and interaction in the schooling path of public students of special education.

In this perspective, it is through the ESA that special education is consolidated, which requires teacher training to develop the function in meeting the new demands that arise at work in front of a special education service that does not have as direction the clinical focus, that is, the students' disability should not be highlighted so that this is a strong impediment to the development of the learning of the same; or by the substitute action of schooling of students with disabilities, global development disorders and high skills/ gifted. Thus, it is necessary that the SEC teacher understands that his goal is to know the student, identify their possibilities and needs, draw up a plan so that they can organize the services, strategies and accessibility resources specific to each student individually.

With this, it is part of the formation of the SEC teacher 
to try to understand and point out the difficulties of the student in order to develop their autonomy and independence, focusing on how this student can be inserted in society as being active and active, able to learn and perform their activities, in their time. This in favor of stimulating the student's awareness that he is able to overcome the characteristics caused by the disability itself, and this will result in a positive impact on society.

For this to occur, it is necessary to have investment and a more consistent qualification that theoretically instrumentalizes the teacher in order to make him prepared for the execution of his role in practice. This training should be based on the National Policy of Special Education in the Perspective on Inclusive Education, which presents guidelines for Brazilian special education, and gives guidance to the regulations and subsequent actions. From it, several documents were in charge of directing the ESA into the Multifunctional Appeal room. This space is placed as a central proposition to support students. In this sense, we approach: the New SEESP/GAB/n. 11/2010 Technique, which presents guidelines for the institutionalization of the ESA offer (BRASIL, 2010b); Resolution CNE/CEB n. 04 of October 2, 2009, establishing the operational guidelines for The ESA in Basic Education, in the modality of special education (BRASIL, 2009); and the New SEESP/GAB/n. 09/2010 Technique of April 9, 2010, which presents guidelines for ESA centers (BRASIL, 2010).

It is worth mentioning that the documents will only be understood as a parameter with the context of their elaboration and when put into practice in the production of life in society.

According to Resolution 4 of 2009, some attributions of the ESA teacher are:

I- Identify, elaborate, produce and organize services, accessibility pedagogical resources and strategies considering the specific needs of students (public - target) of special education;

II- Develop and execute specialized educational care plan, evaluating the functionality of pedagogical and accessibility resources;

III- Guide teachers and families on the pedagogical and accessibility resources used by the student;

IV- Teach and use assistive technology in order to expand students' functional skills, promoting autonomy and participation

V- Establish articulation with teachers in the common classroom, aiming at the availability of services, pedagogical and accessibility resources and strategies that promote the participation of students in school activities.

Therefore, it is observed that, in the attributions, there is no mention related to the teacher's training in guidance and mobility. It is understood that these skills are necessary to help the student to be able to guide themselves in their activities of daily living.

Finally, regarding the teacher's education, it is necessary to be aware of the feasibility of continuing teacher education, especially in relation to guidance and mobility, and, with this, the ESA teacher should seek this professional complementation.

\section{Methodology}

This research aimed to point out the importance of Orientation and Mobility aimed at people with visual impairment as an important training for the ESA professional, and it is pertinent to describe relevant terms related to this theme. This wasall oriented by a qualitative approach, because it is the appropriate way to understand the nature of a social phenomenon. In the same line used by Flick (2004), is Marques (2006) in defending that the qualitative approach is one in which the data are not able to be measured mathematically. Therefore, understanding reality through a qualitative approach is to understand it from the subjectivity of the subjects-participants of the investigation.

This work is also characterized as a bibliographical research, which consists of making a survey of several bibliographies already published in the form of books, articles and magazines, with the purpose of putting the researcher in direct contact with everything that was written on a given subject. This exercise makes the researcher a connoisseur of the information already produced, contributing to find the most appropriate course for the purposes of his research (MARCONI; LAKATOS, 1992; SEVERINO, 2007).

In this context, literature focused on the theme of Guidance and Mobility was used, as well as addressing other topics, such as special education, social inclusion, accessibility and visual impairment, based on the SpecializedEducational Care(ESA) d iretriz, which "[...] its function is to identify, develop and organize pedagogical and accessibility resources that eliminate barriers to full participation of students, considering their specific needs" (BRASIL, 2008a, p. 10).

\section{Results and Discussion}

In the process of development and execution of methodological actions and searches carried out, after composition of the theoretical framework and definition of strategies to achieve the objectives foreseen in the research project, we consider, as a result of the research, the little training of teachers in the area of visual impairment and the relevance of training in Guidance and Mobility of the ESA teacher.

It has been observed that there are few Resource Rooms in which there is the Guidance and Mobility program or something like it. It was noticed that there was no clear definition of what would be the functions of the teachers of the Resource Rooms in relation to Guidance and Mobility. It was also seen that, in some studies with interviews with ESA teachers, there was a certain discomfort when it came to Guidance and Mobility, because teachers felt unprepared for the development of the program, some mentioned that they did not have enough time to perform orientation and mobility activities with their students, since they have many and cannot handle it.

Thus, it is evident the real need to have training and 
training of these professionals in relation to the Orientation and Mobility program. Training and professional training is indispensable, because it is through them that there is a search for improvement in actions pertinent to the profession. Thus, the teacher needs to seek to train and have training in Guidance and Mobility, in order to develop skills and competencies capable of approaching this program with their students, establishing the activities that are necessary for the integral and harmonious development of students with visual impairment, planning individually and collectively, addressing the singularities and characteristics of each one.

Competent and qualified teachers are essential for the construction of inclusive education in order to combat educational exclusion and promote the social inclusion of people with disabilities, in this case, of people with visual impairment. It is necessary to recognize and value diversity as a factor for enriching the educational process, promoting changes in school and teacher education, aiming at a restructuring of education that benefits all students, favoring educational experiences among all of them.

The specialized educational care seeks to identify, elaborate and organize pedagogical and accessibility resources that eliminate the obstacles to the complete participation of students, considering their specific needs, and working on them, within the uniqueness of each individual. This should be done in order to autonomy and independence wherever the individual is inserted. Thus, the visually impaired person, a person inserted in the scope of the ESA, should receive such care effectively, and teachers are required to deal with this population.

Understanding that visual impairment compromises the ability to move with independence and autonomy, also affecting the acquisition of concepts, interaction with oneself and with others and, consequently, with the environment, one perceives the importance of direct monitoring of the person with visual impairment by someone instructed and aware of their limitations, and who knows how to offer the appropriate guidelines to exercise locomotor independence. The teacher needs to know how to proceed to assist this student, what resources he can use in his activities with the student, how to stimulate the development and independence of the student.

The Guidance and Mobility program helps the visually impaired to develop and re-establish the ability to be independent and to be able to move safely from one place to another, causing the visually impaired person to get used to going through some places, they become familiar, and he adapts to be independent in his locomoted and walk making use of resources and means that help him to get around better. Therefore, the need for the teacher to know this program and put into practice the same with people with visual impairment that he will attend, eliminating barriers that hinder or prevent the participation and learning of all, leading the individual to become able to develop activities that were not possible before.

It is understood that the training of the ESA teacher in Guidance and Mobility brings numerous benefits, both for the teacher and for the assisted student, since together they can find educational means that will promote a better quality of life. In this way, the assisted student will be able to develop his autonomy and independence, maturing his concept of space and his adaptation and locomotion through which to walk, as well as learn to use effective instruments and means to assist him in this process. This, consequently, will increase your selfesteem and safety with yourself, bringing benefits to your physical and mental health. With regard to the teacher, he will feel more confident and safer to approach his visually impaired students, as well as will have more resourcefulness to promote educational methods that assist his students, addressing each case in the way that best fits.

\section{Conclusions}

It is relevant and fundamental to reflect on GM, in what is necessary for professionals in its implications as a way to assist the applications of these practices and reaffirm the importance of training in this area, for teachers in the ESA classroom. The practices and techniques of GM are of great value and importance for the independence of people with disabilities.

For the disabled to master the various techniques of Guidance and Mobility (GM) and to achieve resourcefulness and safety in their movements, it is necessary to have several physical exercises and motor activities that seek balance, as well as develop their motor skills (thin and thick) that will enable the various movements of the day-to-day of this individual. For this to occur, it is crucial to monitor and stimulate a qualified ESA professional, to assist him in such activities and monitor his development and maturation.

We understand that the performance of the teacher of the ad room in view of this training, will represent an important way to enable the development of the visually impaired person in the action of getting away with maximum safety and independence within the school environment. And in view of this, our research is justified, because the teacher having knowledge of inclusive pedagogical practices of the ESA, will enable a large participation of students, facilitate learning and accessibility.

It is understood that the more people know appropriate conducts and procedures in relation to Orientation and Mobility, one can have a better interaction with visually impaired people, and this will contribute to the process of social inclusion.

Through the literary review, it was evidenced the importance of the preparation of the ESA teacher focused on the Orientation and Mobility program, since such preparation will make it have scientific basis and sufficient knowledge to help the person with disabilities, taking into account that this aid had led the disabled person to better understand their space, to develop their autonomy and independence, to move around and move more safely. Thus, it becomes evident the need for an organized school environment, including teachers with adequate training to practice their pedagogical.

This research can evolve in the future, being developed in a practical way, through the observation of ESA teachers trained in Guidance and Mobility assisting and accompanying people with visual impairment, and evaluating the positive impacts of the training of these teachers in the life and locomotor development of these people. 


\section{References}

[1] BRAZIL. Ministry of Education. National guidelines for special education in basic education / Secretariat of Special Education - MEC, 3rd edition: SEESP, 2001

[2] BRAZIL. Ministry of Education. Secretariat of Special Education. Law No. 10,098 of December 19, 2000. Guidance and Mobility: Basic knowledge for the inclusion of the visually impaired. Elaboration Edileine Vieira Machado... [et al.] Brasilia: MEC, SEESP, 2003. 167 p.

[3] BRAZIL. Law No. 13,146 of July 6, 2015. It establishes the Brazilian Law for the Inclusion of Persons with Disabilities (Statute of Persons with Disabilities). Available from: $<$ http://www.planalto.gov.br/ccivil_03/_Ato2015-2018/2015/ Lei/L13146.htm>. Access: 26 Jun. 2020.

[4] CARLETTO, Marcia Regina Vissoto. The PDE teacher and the challenges of the public school of Paraná. Curitiba: SEED/PR., 2007. V.1. (PDE Notebooks). Available from: $<$ http://www.diaadiaeducacao.pr.gov.br/portals/cadernospde/p debusca/producoes_pde/2007_unioeste_edespecial_artigo_ma rcia regina vissoto carletto.pdf $>$. Access on Jun 26. 2020. ISBN 978-85-8015-037-7.

[5] NATIONAL BOARD OF EDUCATION. RESOLUTION No. 4, OF OCTOBER 2, 2009. Establishes Operational Guidelines for Specialized Educational Care in Basic Education, Special Education modality. Available in: http://portal.mec.gov.br/dmdocuments/rceb004_09.pdf>. Access: 26 Jun. 2020.

[6] ENGO, L.M.; SEABRA JÚNIOR, M.O. \& CASTILHO, J.M.C. Technique with Seer Guide: Performance Evaluation Support. Revista da Sobama, Marília, v. 15, n. 2, p. 25-30, Jul./Dec., 2014

[7] FLICK, U. An introduction to qualitative research. Porto Alegre: Artmed. 2004.

[8] GARCIA, N. Orientation and Mobility Programs in the process of education of children with blindness. Doctoral thesis, FEUSP/SP, 2001.

[9] HOFFMANN, Sonia B. Benefits of orientation and mobility intercultural study be-tween Brazil and Portugal. Benjamin Constant Magazine, Rio de Janeiro, year 5, n. 14, p. 11-16, Dec. 1999. Available at: $<$ http://www.ibc.gov.br/?catid=4\&itemid=56>. Accessed: 22 Oct. 2012.

[10] MACHADO, Rosângela. Resignify special education in basic education: policies, paradigms and practices. Campinas, SP: [s.n,], 2006.

[11] MARCONI, Marina de Andrade; LAKATOS, Eva Maria. Methodology of scientific work. São Paulo: Atlas Publishing House, 1992. 4th ed. p.43 and 44.

[12] MARQUES, H. R.; MANFROI, J.; CASTILHO, M. A. de; NOAL, M. L. Methodology of research and scientific work. Campo Grande: UCDB, 2006.

[13] MATOS, Elizete Lúcia Moreira; MUGIATTI, Margarida Maria Teixeira de Freitas. Hospital pedagogy: Humanization integrating education and health. 6th ed. Petrópolis: Voices, 2012 .

[14] MENDONÇA, Artur José Braga De; Matos, Isabeli Sales (The Training of the Professional of Guidance and Mobility in Brazil: Knowledge andPractice. Lisbon, Portugal. April 2019.
[15] MENDONÇA, Alberto et al. Blind and low-visionstudents: curriculum guidelines. 2008.

[16] MENDONÇA, Artur José Braga de. ANAMNESE - STEP LEADING UP TO THE DEVELOPMENT OF A PROGRAM OF ORIENTATION AND MOBILITY. In: FEAT, Agebson Rocha; FREITAS, Lucineide Penha Torres de (Organizers). Guidance and Mobility: tests. Fortaleza: IFCE, 2018. p. 35-47.)

[17] TECHNICAL NOTE No. 11 / 2010 / MEC / SEESP / GAB. Subject: Guidelines for Institutionalization in School, the Offer of Specialized Educational Care - ESA in Multifunctional Resource Rooms. Date: May 7, 2010

[18] SECRETARY OF ACCESSIBILITY UFC. Accessibility Concept. Ceará, 2010. Available from: $<$ http://www.ufc.br/acessibilidade/conceito-de-acessibilidade $>$ Acesso: 26 Jun. 2020.

[19] SEESP/MEC - Ministry of Education Secretariat of Special Education. Operational guidelines of special education for educational care specialized in basic education. 2018. Available in:

http://portal.mec.gov.br/index.php?option=com_docman\&vie 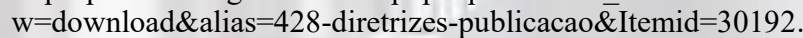 Accessed: 26 June 2020.

[20] SEVERINO, Antonio Joaquim. Methodology of scientific work. 23. ed. rev. and current. São Paulo: Cortez, 2007.

[21] SOUZA, Ana Paula Cunha de. Challenges for accessibility to public spaces in social inequality. World Magazine Social and Humanities. Curitiba, PR, v. 2, n. 1, 21, Jan./Jul., 2017.

[22] WEISHALN, R. Orientation and mobility in the blind children. New York: Englewood Cliffs.

[23] ZENGO, L.M; S. JUNIOR, M.O; MOREIRA, J.C.C. Future teachers: Exergames as an educational resource. Colloquium Humanarum, vol. 11, n. Especial, Jul-Dec, 2014, p. 894-- 902. Available

in: $<$ http://www.unoeste.br/site/enepe/2014/suplementos/area/Hum anarum/Educa $\% \mathrm{C} 3 \% \mathrm{~A} 7 \% \mathrm{C}$ 3\%A3o/FUTURES\%20TEACHERS.pdf>. Access on Jun 28. 2020. 